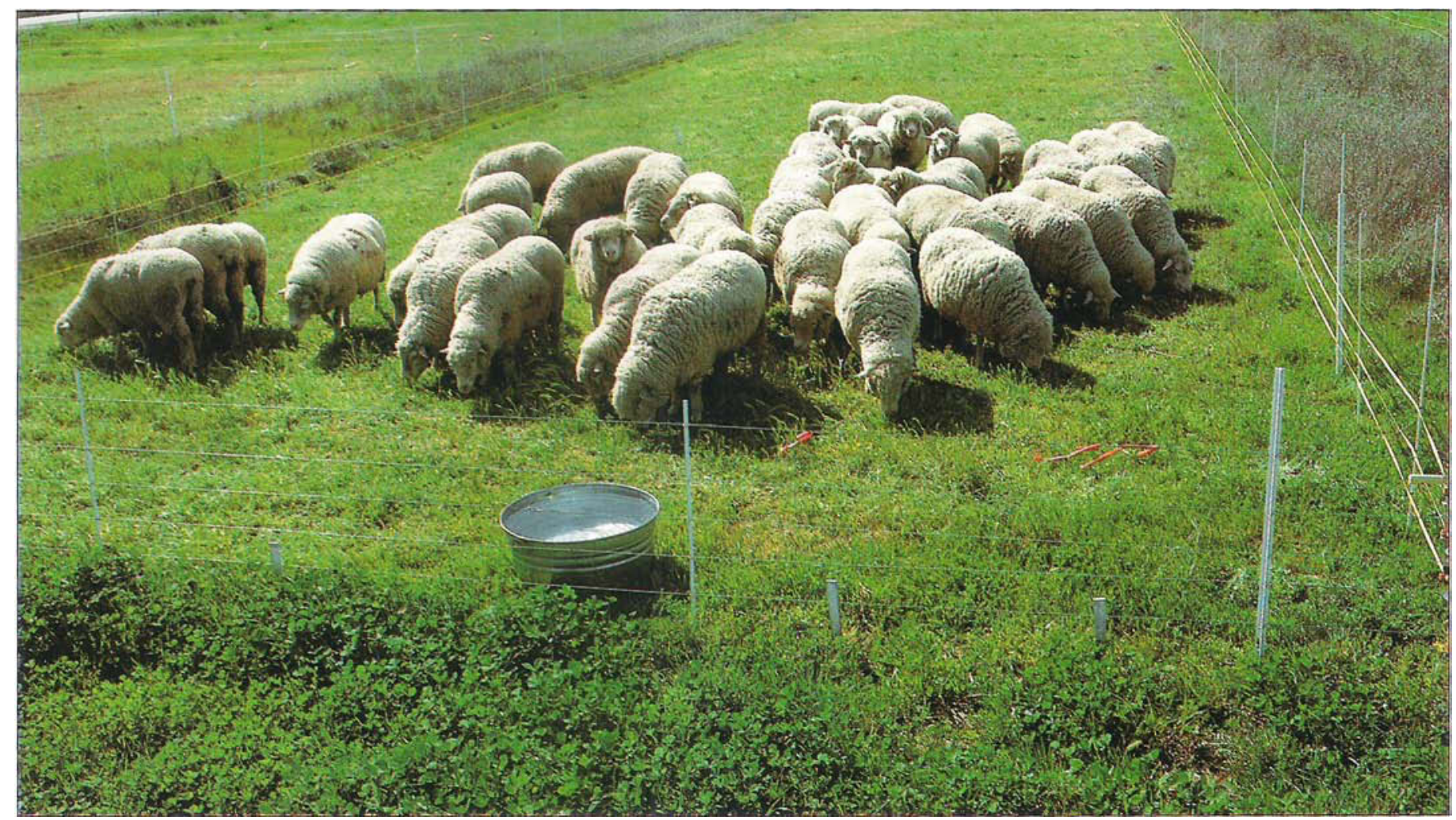

Flock of $\mathbf{4 0}$ ewes graze yellow starthistle during rosette stage of growth, UC Agronomy Farm, March 1990.

\title{
Controlled grazing on annual grassland decreases yellow starthistle
}

\begin{abstract}
Craig
D. Thomsen

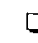

William A. Williams

๑ Marc Vayssiéres

$\square$

Fremont L. Bell

a Melvin R. George
Since its accidental introduction in the mid-1800s, yellow starthistle (Centaurea solstitialis), a noxious weed, has steadily spread throughout California and now infests 8 million acres. It continues to invade new areas, and although it is a major source of summer nectar for bees, its spiny flowers, toxicity to horses, invasiveness and ability to form impenetrable stands make it one of the state's most troublesome weeds.

Because of its spiny flowerheads, it is often assumed that livestock grazing to manage infestations is not an option. It is true that horses should not be allowed to graze starthistle because it is poisonous to them, but the pre-spiny stages are acceptable in the ruminant diet, and animals readily graze nonspiny plants, along with other herbage. In much of California, yellow starthistle germinates with autumn rains, but it does not usu- ally become spiny until May or June, leaving up to 6 months when it can be grazed to manage infestations.

For 4 years we have studied cattle, sheep and goats to determine whether their grazing can control yellow starthistle in grassland. Our hypothesis: heavy defoliation at specific stages of development suppresses growth, survivability and reproductive output. We also considered palatability and nutritional value, differences in livestock eating habits, the timing and frequency of grazing, starthistle recovery following defoliation, population dynamics of starthistle, rainfall influences, condition of paddocks after grazing and responses from associated vegetation.

In California Agriculture, SeptemberOctober 1989, we reported the first-year results of cattle grazing and the use of 2,4-D to control starthistle. Later, we dis- 


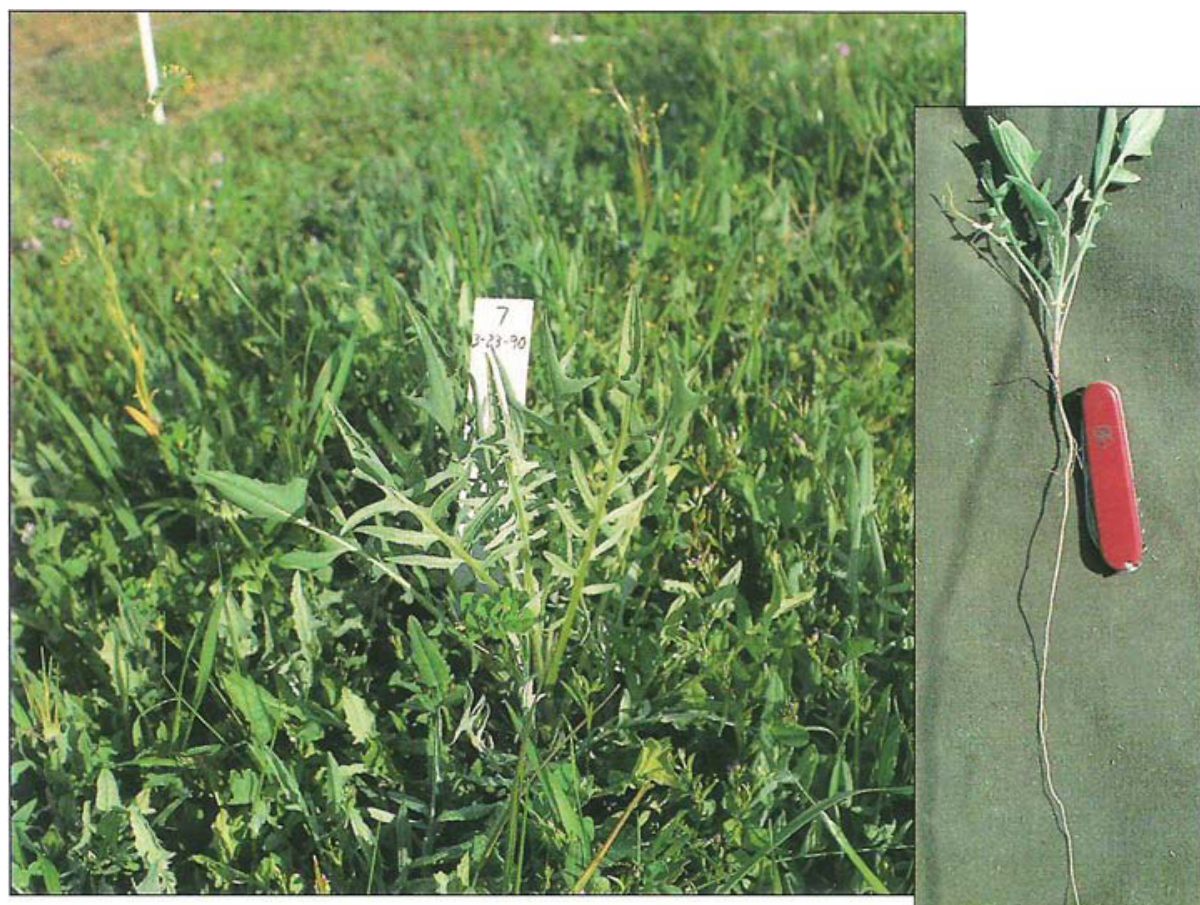

Rosette stage of growth observed in March 1990. Inset: Portion of tap root is seen in rosette stage of growth.

\section{Arrowhead Ranch experiment}

The site of the experiment in cattle grazing was Arrowhead Ranch located in Colusa County, 35 miles northwest of Williams in the Inner Coast Ranges at 1,300-foot elevation. Annual precipitation measured by the nearby Forest Service station at Stonyford ranged from 12 to 19 inches over the test period. The ranch is used as spring and summer range and consists of annual-type grassland with scattered blue and valley oaks. More than 70 species of annual plants were recorded on the 4.5-acre experimental site, but starthistle dominated it. In some portions, initial starthistle seedling densities exceeded 1,000 per $\mathrm{m}^{2}(800$ per $\mathrm{yd}^{2}$ )

The site was divided into half-acre paddocks. The main treatments consisted of grazed and ungrazed paddocks, replicated three times. Grazing periods were initiated in late spring (May 25), when starthistle is in the bolting, pre-spiny stage and two to three biweekly follow-up grazings were used to consume the regrowth. Stock densities were $18 \mathrm{cow}$ calf pairs per half-acre. Initial grazing periods ranged from 12 to 24 hours per paddock and declined to 8 hours or less for the last grazing period. After each grazing period, the cattle were put out in the open range until they were needed again. Cattle were excluded from the ungrazed treatments throughout the study.

Three other paddocks had locally dense stands of hardinggrass and were used as demonstration plots to assess the effects of time-controlled grazing on vigor, seedling establishment and the competition of hardinggrass against starthistle, but those observations are not presented here.

\section{Grazing effective at Arrowhead}

Grazing in all 3 years significantly reduced starthistle flowerhead densities (table 1), and there were decreases in canopy densities of more than $90 \%$ in 2 of the 3 years. Grazed plants that were not killed outright were severely stunted (6 to 12 inches). The ungrazed paddocks supported mature starthistle that formed

TABLE 1. Yellow starthistle flowerhead densities for grazed $(3 x, 4 x, 3 x)$ and ungrazed treatments in 1989, 1990 and 1991 (Colusa County) lings that emerged the following growing season were counted at the Agronomy Farm site at UC Davis to monitor changes in the seedbank.

At the site of the cattle experiment, there was considerable variability in soil, microtopography and baseline starthistle densities, so paddocks were stratified using geostatistics to adjust for this variability.
Means followed by different letters are significantly different $(p<.05)$. Based on rank transformation of the data.

*Actual quadrant size $0.1 \mathrm{~m}^{2}$

\begin{tabular}{lccc}
\hline \hline Treatment & 1989 & 1990 & 1991 \\
\hline & $\ldots \ldots \ldots \ldots . .$. & flowerheads $/ \mathrm{m}^{2 *}$ & $\ldots \ldots \ldots .$. \\
Grazed & $82 \mathrm{a}$ & $23 \mathrm{a}$ & $192 \mathrm{a}$ \\
Ungrazed & $558 \mathrm{~b}$ & $255 \mathrm{~b}$ & $843 \mathrm{~b}$ \\
\hline
\end{tabular}
subdivide our experimental pastures we used New Zealand-style electric fencing. 
dense spiny thickets 2 to 3 feet tall with flowerhead densities 4 to 11 times greater than in grazed paddocks.

Although more than 70 plant species were recorded on site, most of them had senesced by the time of the initial grazing, and starthistle was the dominant species that was still green, with lesser amounts of purple vetch (Vicia benghalensis), curly dock (Rumex crispus), hardinggrass (Phalaris tuberosa var. stenoptera),

California poppy (Eschscholzia californica) and milkweed (Asclepias eriocarpa). With the notable exception of milkweed, which the animals consistently avoided, all the plants were readily grazed, including the bolting starthistle. Starthistle was heavily defoliated and the upright stalks were stripped of their manybranched flowering stems. During grazing, animal behavior was closely monitored, and the cattle were moved when they showed no further interest in grazing. In general, this occurred when fresh forage was depleted and the paddocks had been fouled by manure and urine.

Initial heavy grazing resulted in some starthistle mortality, but most plants regrew from basal and axillary buds. The regrowth also flowered, so it was essential to closely monitor and regraze them before spines appeared. For best results, this grazing window lasted between 2 and 3 weeks. In 1991, when nearly a month had passed between the first and second grazing, many plants reached the spiny stage by the time the animals returned; consequently, those plants were not grazed, resulting in the high flowerhead densities.

The year-to-year fluctuations in flowerhead densities also reflect the amount and timing of rainfall. For example, the nearly 10 inches of rainfall in March 1991 was associated with increased densities in the ungrazed treatments, compared with previous years, when spring moisture was more scarce.

\section{Agronomy Farm test}

Grazing by sheep and goats was tested on the Agronomy Farm at UC Davis to compare starthistle responses to grazing at the early (rosette) and lateseason (bolting) stages. Along with a large component of starthistle, resident vegetation included annual grasses and
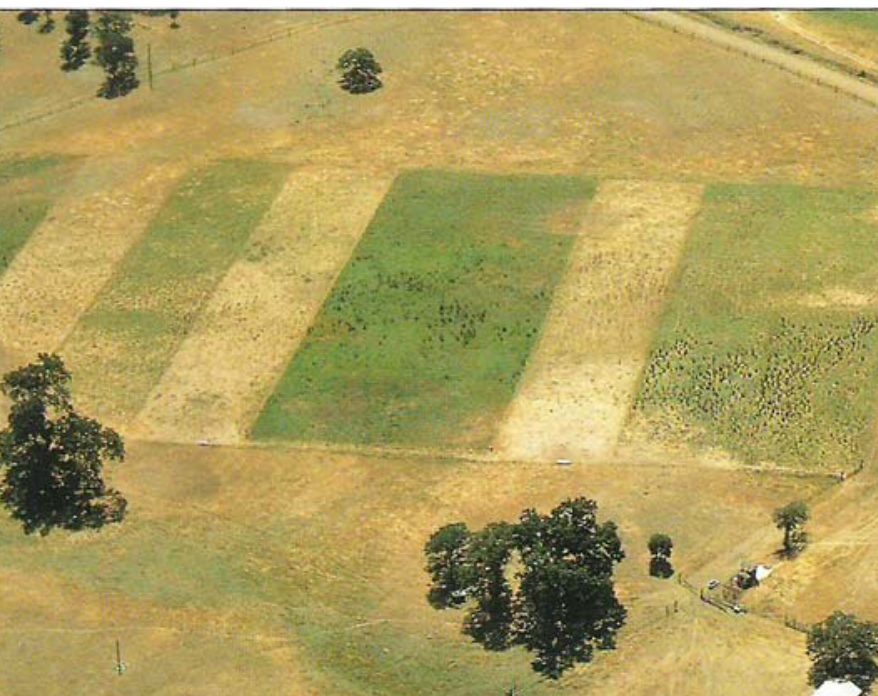

At Arrowhead Ranch in Colusa County, July 1992, paddocks 2, 4 and 7 (left to right) show the effects of cattle grazing on removal of yellow starthistle. The other paddocks (controls), characterized by green vegetation, are dominated by yellow starthistle. The darker green clumps are hardinggrass. The area outside of the experimental paddocks is continuously grazed during spring and summer and also shows starthistle reduced by cattle grazing.

legumes with small amounts of annual and perennial forbs. Initial densities of starthistle ranged from 90 to 230 seedlings $/ \mathrm{m}^{2}$ in the eight paddocks. Annual precipitation ranged from 12 to 17 inches.

Following a pilot study in 1989 to determine the feasibility of using sheep, we assessed starthistle response to sheep grazing during the rosette stage the next year. We compared intensive sheep grazing ( 20 to 40 ewes per 0.1 acre) with a no-grazing treatment replicated four times. The grazed treatment consisted of three periods of short-duration, highintensity grazing (40 ewes initially) at the rosette and pre-bolting stage of development and regrowth. The initial grazing occurred March 23; 3 weeks later grazing was repeated, and 2.5 weeks after that (May 3 to May 5, 1990) the final grazing occurred. Because there was less biomass after the first grazing, we reduced sheep numbers to 20 and reduced the grazing time.

\section{Agronomy Farm results}

Repeated grazing of starthistle before flowering did not suppress the final reproductive output (table 2A). Actually, flowerhead densities in the grazed paddocks were higher than in the ungrazed treatments $(p=0.05)$, despite the three heavy grazings from late March to early May. (This may have been because

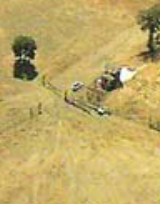

branching was enhanced, but we did not measure it.) The starthistle component in the forage ingested was estimated to be $35 \%$ in the first grazing, $75 \%$ in the second grazing and more than $90 \%$ in the third grazing. The increasing percentage reflects the reduced biomass of associated plants and starthistle's better ability to recover following defoliation. During each grazing, the sheep uniformly grazed the vegetation, and all of the starthistle was grazed close to the ground. Starthistle recovery and regrowth, relatively slow because of the drought, still far outpaced that of associated plants.

In spring 1991, 17 goats grazed the same paddocks used by sheep in previous years. As in the cattle experiment, initial grazing was timed to starthistle's bolting stage (May 15). Although bolting had begun, many plants were still in the rosette stage and formed a dense understory beneath bolting plants. Much of the other resident vegetation had senesced and was no longer green. The goats selectively grazed the upright, bolting plants but left the rosettes uneaten. This selectivity was striking in contrast to the sheep, which routinely grazed plants in the rosette stage. After the goats were removed, regrowth from the previously grazed stalks was slow because of the drought. The ungrazed rosettes that had remained vegetative appeared moisture-stressed. When the goats were returned 3.5 weeks later they showed little interest in grazing and only nibbled at the unspiny regrowth and moisture-stressed rosettes, avoiding the relatively few plants with spines.

In spite of the sparse grazing that occurred during the second grazing, a 14fold reduction in flowerhead densities resulted (table 2B). Moreover, starthistle seedling densities sampled in February 1991 before the goat grazing were three times higher in the grazed paddocks than in ungrazed paddocks (table 3A). The fewer number of grazings required with goats compared with cattle was associated with the drought's severity.

\section{Palatability differences}

Differences in animal acceptance of starthistle were observed, but comparisons are qualitative because of site dif- 
ferences, timing of grazing, number of years animals were in the study, origin and age of the animals, and their dietary history. Nevertheless, the following observations are presented. The cattle readily grazed both early (rosette) and late stages (bolting, pre-spiny stalks) and also grazed the regrowth from bolting plants. The cattle had had previous experience grazing starthistle, whereas the previous diet of the sheep and goats was largely alfalfa hay and pellets.

In the first-year pilot study with sheep, two flocks of sheep were used. The first flock, consisting of lambs, began grazing in the paddocks when starthistle was bolting. Arrowleaf clover (Trifolium vesiculosum), a tall upright clover, was especially abundant that year and the lambs selectively grazed it and showed little interest in the starthistle. A different flock of lambs was put in immediately after the first flock left and they unhesitatingly grazed the bolting starthistle. The flock was then removed and fed alfalfa hay and pellets until a repeat grazing 2 weeks later. When they returned to graze the regrowth, the lambs showed little interest in further grazing.

In the second year of the sheep trial, ewes were used. They readily grazed rosettes and the regrowth two times (table 2A), but were not tested under a late grazing regime. Given this and the diet of alfalfa hay and pellets the lambs were normally fed, it is difficult to draw conclusions from our research about sheep acceptance of starthistle in later stages of growth. Nevertheless, we have observed many localities outside of our trials where sheep have routinely grazed starthistle late in the season, effectively reducing dense stands.

Unlike the sheep, the goats showed a strong preference for bolting plants and ignored plants in the rosette stage. During the second grazing, they demonstrated little interest in the regrowth as well as the previously ungrazed plants. Their initial selectivity for the later growth stage may be linked to their feeding behavior as browsers and their tendency to prefer upright plants.

In general, we observed that palatability and animal acceptance of starthistle decreased after bolting plants had been grazed, with cattle being the most willing to heavily defoliate the recovered plants. In one year of the cattle study, they grazed starthistle four times between May 15 and July 3.

\section{Timing to suppress starthistle}

Yellow starthistle's ability to regrow following defoliation during much of its life cycle surpasses that of most, if not
TABLE 2. Densities of yellow starthistle flowerheads $(A)$ after sheep grazing $(3 x)$ initiated in the rosette stage in 1990, and (B) after goat grazing $(2 x)$ in the bolting stage in 1991, UC Agronomy Farm

\begin{tabular}{lcc}
\hline \hline & $\begin{array}{c}\text { A } \\
\text { Sheep } \\
1990\end{array}$ & $\begin{array}{c}\text { B } \\
\text { Goats } \\
1991\end{array}$ \\
\hline Treatment & $\ldots \ldots$. flowerheads $/ m^{2} \ldots \ldots .$. \\
Grazed & $266 \mathrm{a}$ & $27 \mathrm{a}$ \\
Ungrazed & $172 \mathrm{~b}$ & $374 \mathrm{~b}$ \\
\hline
\end{tabular}

Means followed by different letters are significantly different $(p<0.05)$. Based on rank transformation of the data.

TABLE 3. Density counts of (A) yellow starthistle seedlings before spring grazing and (B) Lupinus bicolor seedlings, February 1992, UC Agronomy Farm

\begin{tabular}{|c|c|c|}
\hline Treatments & $\begin{array}{c}\text { A } \\
\text { Starthistle }\end{array}$ & $\begin{array}{c}\text { B } \\
\text { Lupine }\end{array}$ \\
\hline & \multicolumn{2}{|c|}{.......... seedlings $/ m^{2}$} \\
\hline Grazed & $1,920 a$ & 371 a \\
\hline Ungrazed & $438 b$ & $18 b$ \\
\hline \multicolumn{3}{|c|}{$\begin{array}{l}\text { Means followed by different letters are significantl } \\
\text { different }(p<0.05) \text {. Based on rank transformation } \\
\text { of the data. }\end{array}$} \\
\hline
\end{tabular}

all, herbaceous plants in California annual grasslands. This is one reason why it is such a successful weed on grazing lands and it explains why only repeated grazing during the most vulnerable growth period can effectively manage infestations.

Along with the basal position of growing buds and a deep rooting habit, late-season soil moisture favors strong starthistle regrowth. Starthistle is not suppressed under an early grazing regime, probably because soil moisture is still available. Moreover, when grazing occurs in young stages of growth, neighboring plants are also defoliated and any competition they may provide is reduced. If grazing pressure occurs at this stage but is not continued beyond it, starthistle flourishes with fewer plants competing.

Under a later grazing regime, starthistle usually recovers somewhat, but decreasing soil moisture and high air temperatures dry it out. After a second or third grazing, many plants no longer have sufficient reserves to continue normal growth and either die or become markedly suppressed. In starthistle-infested areas, cattle or sheep operations that have animals grazing during late May, June and early July can be expected to support lower amounts of starthistle than operations where animals are removed in mid-May after the cool-season annuals have completed their life cycle and starthistle is still actively growing.

\section{Timing and residual dry matter}

One of our considerations was the amount of residual dry matter that remained on the soil surface following grazing. Residual dry matter is used as a basic measure of range health, because it protects the soil and enhances forage production in the following growing season. With early grazing, associated plants were grazed, along with starthistle, and little residual dry matter was left, resulting in a bare, exposed soil surface. With late-season grazing, animals preferred grazing starthistle to grazing the dried annuals, and sufficient residue - well above the recommended minimum - was maintained on the soil surface.

\section{Effects on botanical diversity}

Grazing enhanced native dicot diversity. For example, at the UC Agronomy Farm, two wildflowers, lupine (Lupinus bicolor) and redmaids (Calandrinia ciliata var. menziessii), were strongly suppressed in ungrazed areas, whereas they were abundant in grazed areas. Samples were taken for lupine and grazing increased its density 20 times (table 3B).

At the Arrowhead Ranch, meadowfoam (Limnanthes douglasii) was abundant in grazed paddocks but was nearly absent in ungrazed treatments. These representative native dicots were evidently intolerant of starthistle shading and the thick thatch that had accumulated in ungrazed paddocks.

The increased starthistle seed production in ungrazed paddocks resulted in higher seedling densities, often exceeding $3,000 / \mathrm{m}^{2}$. This level of intense competition also suppressed many species that were more abundant with grazing.

\section{Conclusions}

Our results show that controlled grazing can effectively manage yellow starthistle stands, provided grazing periods are closely timed to starthistle's bolting, pre-spiny stage and that one to three additional grazings are used to remove regrowth. The number of grazings required to suppress. plants increased when spring rains replenished soil moisture. Timing of grazing was critical and more important than animal class, but there were differences in acceptance of starthistle by cattle, sheep and goats.

Although starthistle has been regarded as having low nutritive value to livestock, our research shows that its strong growth, palatability, protein levels and resilience make it a useful forage before spine production. Because it continues to grow after most other annual range plants have senesced, it provides green forage in late spring and early 


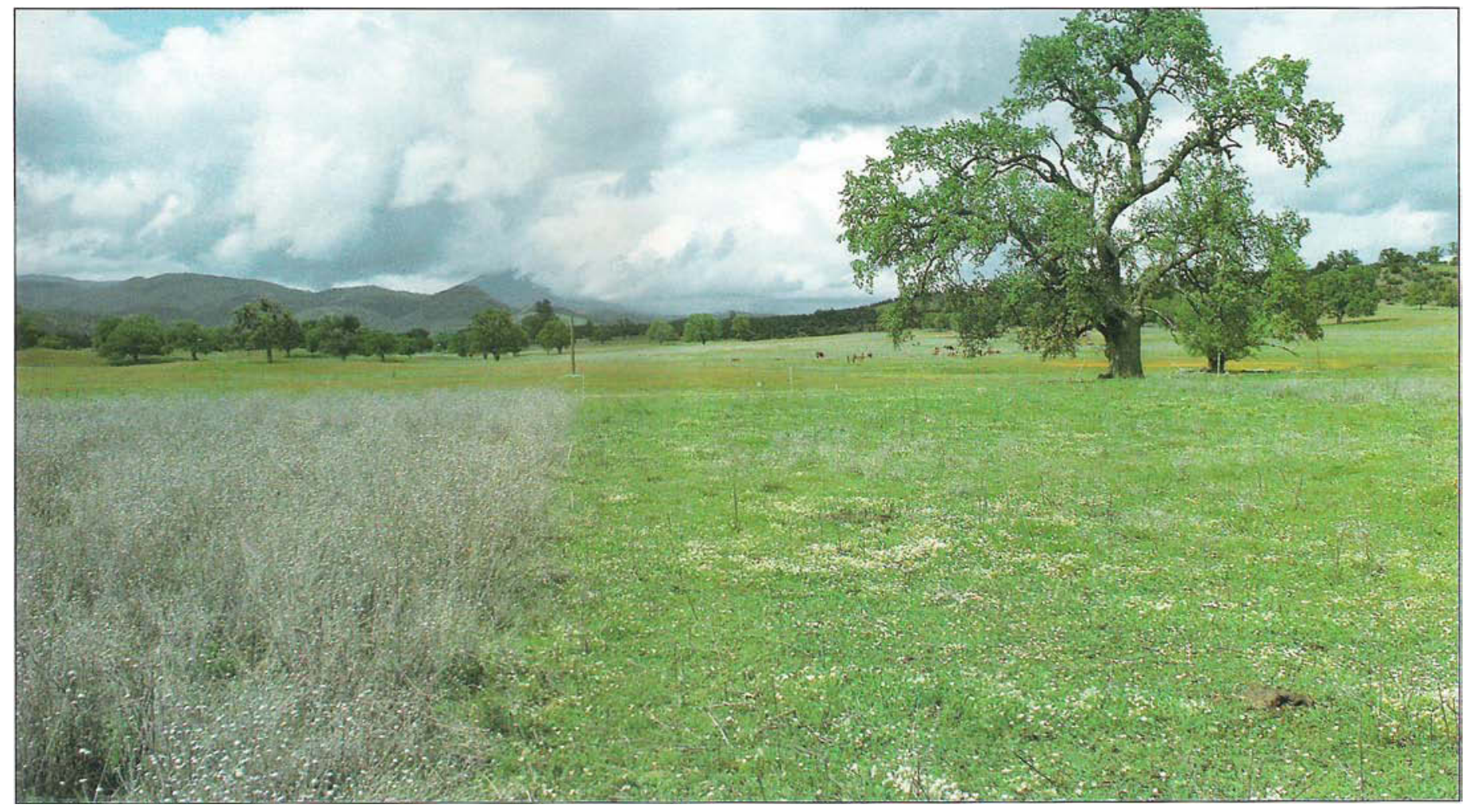

Left, yellow starthistle skeletons in ungrazed paddock.

Right, cattle-grazed paddocks with meadowtoam, Limnanthes douglasit, April 1992.

summer when other green forage is generally unavailable. The amount of biomass present varied, but at one site pre-grazing starthistle biomass exceeded 4,000 pounds per acre dry matter in late May.

When grazed during the bolting stage, flowering and spine production are delayed and the period during which starthistle can be grazed is extended. When bolting plants are not grazed, starthistle quickly develops the stout hard spines that prevent livestock grazing.

Although yellow starthistle has forage value to ruminants, we do not recommend encouraging its proliferation. Left uncontrolled, starthistle has demonstrated the ability to spread and increase in density to the exclusion of other spe- cies, both native and alien. Ungrazed stands often produce impenetrable thickets of starthistle that remain through summer and fall and decrease plant species diversity the next growing season.

Grazing between mid-May and early July resulted in major reductions in plant biomass, canopy size and seed production, but sufficient seed was produced or already existed in the soil seedbank for some new plants to establish in subsequent years. Properly timed grazing effectively managed infestations and made use of starthistle as forage, but additional control measures are necessary to further reduce populations. There is no practice that is certain to eradicate well-established starthistle infestations on rangelands, and long-term management of starthistle requires use of these or other practices on a more or less permanent basis.

C. D. Thomsen is Staff Research Associate, W. A. Williams is Professor Emeritus, and M. Vayssiéres is Graduate Student, Department of Agronomy and Range Science, UC Davis; F. L. Bell is Farm Advisor Emeritus, Glenn and Colusa counties; M. R. George is Range and Pasture Extension Specialist, Department of Agronomy and Range Science, UC Davis.

The authors thank Randy and Kathy Salveson for use of their land and cattle, and for their hospitality, and Ladonna Foley, Dan Brown, Dana Van Liew and Roy Hull for their cooperation and assistance with the dairy goats and sheep. This project was supported by a grant from UC/IPM.

\section{CALIFORNIA AGRICULTURE ASSOCIATE EDITORS}

Animal, Avian, Aquaculture
and Veterinary Sciences
Richard H. McCapes
(2nd assoc. editor to be announced)
Economics and Public Policy
Harold O. Carter
Alvin Sokolow
Food and Nutrition
Barbara Schneeman
Eunice Williamson
Human and Community Development
Linda M. Manton
Karen P. Varcoe

Land, Air \& Water Sciences

Garrison Sposito

Henry J. Vaux, Jr.

\section{Natural Resources}

Daniel W. Anderson John Helms

Richard B. Standiford

Pest Management

Michael Rust

Frank Zalom

Plant Sciences

Calvin O. Qualset

G. Steven Sibbett

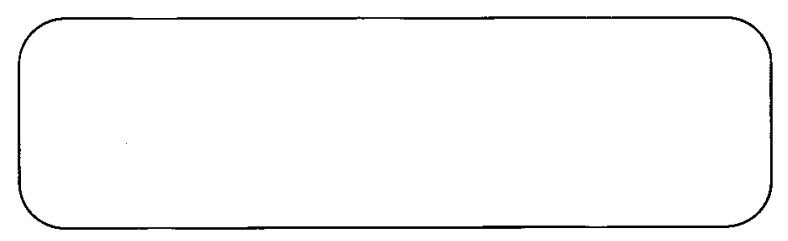

